\title{
Commentary \\ Improving care by understanding the way we work: human factors and behavioural science in the context of intensive care
}

Nick Sevdalis ${ }^{1}$ and Stephen J Brett ${ }^{2}$

\author{
${ }^{1}$ Clinical Safety Research Unit, Department of Biosurgery and Surgical Technology, Imperial College London, 10th Floor, QEOM Building, St Mary's \\ Hospital, South Wharf Road, London W2 1NY, UK \\ ${ }^{2}$ Centre for Perioperative Medicine and Critical Care Research, Department of Anaesthesia and Intensive Care, Hammersmith Hospital, Imperial \\ College Healthcare NHS Trust, Du Cane Road, London W12 OHS, UK
}

Corresponding author: Nick Sevdalis, n.sevdalis@imperial.ac.uk

Published: 29 April 2009

This article is online at http://ccforum.com/content/13/2/139

(C) 2009 BioMed Central Ltd

Critical Care 2009, 13:139 (doi:10.1186/cc7787)

See related research by Fackler et al., http://ccforum.com/content/13/2/R33

\begin{abstract}
Effectiveness and efficiency of care of the critically ill patient are subject to a number of systemic influences, including skills of individual physicians/nurses (technical and non-technical), teamworking in the intensive care unit (ICU), and the ICU environment. We first discuss the paper of Fackler and colleagues as a contribution to the systems approach to clinical performance in the context of intensive care. We then highlight features of care delivery that are unique to intensive care and discuss the need for better understanding of human and non-human elements of the system of care of the critically ill patient as a driver for improvement of care delivery.
\end{abstract}

The past few years have seen a dramatic increase in the literature of papers investigating behavioural issues in relation to care delivery. A range of topics are being addressed, with communication between health care professionals being perhaps the most-researched aspect of health care workers' behaviour. Increasing focus on and awareness of safety issues in care delivery as well as recent changes to clinical practice (for example, European Working Time Directive) and training (for example, high-fidelity simulators) have provided the impetus for this surge in behavioural evidence on the role of 'human factors' in health care contexts.

In the present issue of Critical Care, Fackler and colleagues [1] published one such paper. The authors used a range of well-established behavioural science tools and methods (cognitive task analysis and observations) to study how tasks are allocated in the clinical environment of the intensive care unit (ICU). Thematic content analysis of observational and interview data generated the following categories:

1. pattern recognition
2. uncertainty management

3. creation and transfer of stories

4. team coordination

5. team communication

6. fragmentary teams

7. shifting teams

8. increasing shift handovers

9. role ambiguity

10. external collaborators.

These categories cover a range of skills (for example, storybuilding and story-telling and intra-team and inter-team communication) and tasks (for example, handovers) required for effective and efficient delivery of care in the ICU.

These findings fit well with the systems approach to human performance in health care environments [2,3]. The systems approach postulates that care processes and patient outcomes are a complex function of a number of factors:

- Individual clinical skills: these include what traditionally has been termed 'technical skills' (for example, diagnostic skill and motor coordination in central line insertion or surgical interventions), but also 'non-technical skills' (for example, decision-making in the face of uncertainty) [4].

- Teamwork: teamworking skills include communication within teams (for example, ICU consultant with nurse) as well as between teams (for example, recovery team and ICU team). Other skills related to teamworking are leadership, team cooperation and back-up behaviours, and other behavioural skills $[5,6]$.

$\mathrm{ICU}=$ intensive care unit. 
Figure 1

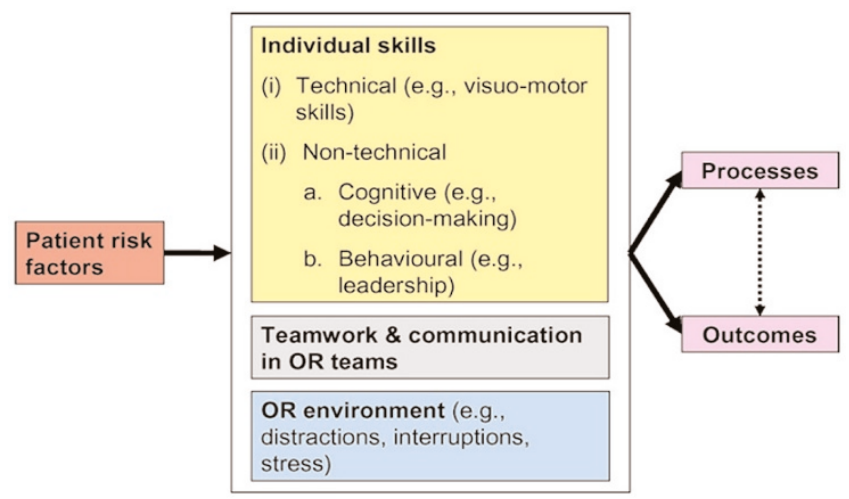

Systems approach to clinical performance and error applied to surgery. OR, operating room. Reprinted from British Journal of Medical and Surgical Urology, Vol 2 ledition number 1, Shabnam Undre, Sonal Arora and Nick Sevdalis, Surgical performance, human error and patient safety in urological surgery, Pages No.9, Copyright (2009), with permission from Elsevier [3].

- Clinical environment: the environment in which care is provided (ICU and operating theatre) $[7,8]$.

Historically, the systems approach has been developed in more detail in the context of surgery (Figure 1), possibly because surgical skills, teams, and environment lend themselves more easily to observation, measurement, and assessment.
Table 1 illustrates the applicability of the systems approach to the ICU. The findings of Fackler and colleagues [1] correspond to all systems components: recognising patterns, making judgements and decisions in the face of considerable uncertainty, and creating stories are all skills of individual clinicians. The team-related issues that the study uncovered reflect the teamwork component of the system. Finally, the structure of the work requires handovers and close work with non-ICU staff.

Table 1 also summarises illustrative evidence from other sources. Firstly, recent research has discovered four interrelated non-technical skills in the context of intensive care: task management, teamworking, situation awareness, and decision-making [9]. Moreover, in the context of critical care, different methods to assess teamworking (for example, selfreport and direct observation) have been reviewed [10] and physicians' versus nurses' perceptions of their collaborative work assessed [11]. Other research has revealed discrepancies in views of communication quality (for example, accuracy and timeliness) between ICU doctors and nurses [12-14], whereas other studies have linked poor communication with increased error potential [15]. Furthermore, the ICU has been analysed as a physical, emotional, and professional work environment [16]. Observational studies of ICUs have shown numerous interruptions, affecting mostly doctors but also nurses [17]. There is an interesting echo here of a previous study from the same institution, which reported that management plans set during ICU rounds were often not understood

Table 1

\section{Systems approach applied to intensive care}

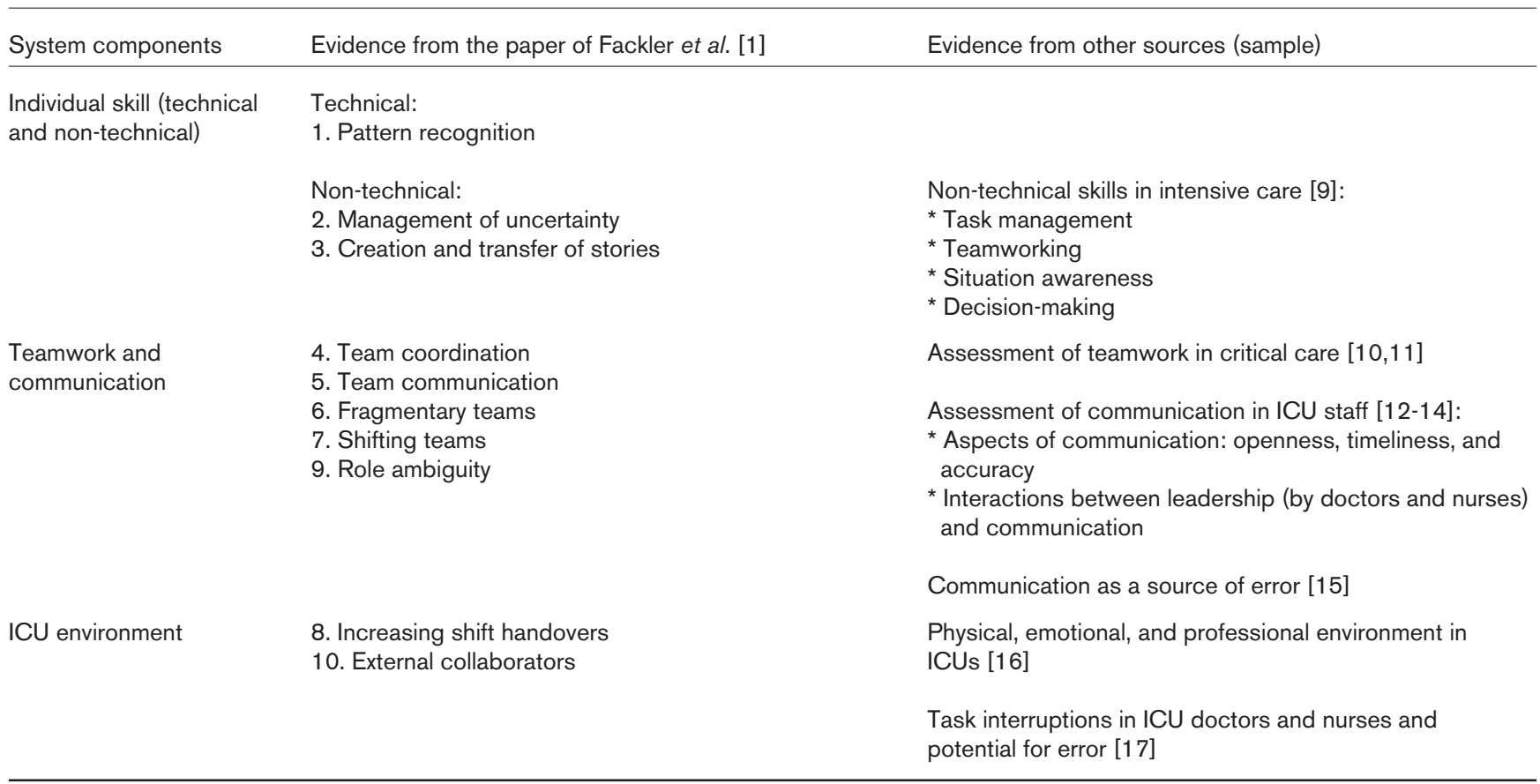

$\mathrm{ICU}$, intensive care unit. 
by nursing and junior medical staff; the introduction of an explicit communication strategy resulted in a clearer understanding of goals, improved outcomes, and shorter lengths of stay [18]. It therefore seems unlikely that the observations of Fackler and colleagues [1] are merely esoteric behavioural descriptions.

A substantial amount of related work has been undertaken in the context of anaesthesia and anaesthesia training, and much of this has been around crisis management (reviewed in [19]). There is an important contextual difference here. Although many patients are admitted to intensive care as a result of or in the middle of some form of crisis, ICU care is predominantly about dealing with consequences or preventing crises. Time frames are different and much activity might be described as routine, albeit complex. Errors leading to adverse events are often related to sporadic failure of routine, loss of key information at handover, and clouding of the narrative of the patients' illnesses. This is a particular issue for long-stay patients; all ICU clinicians will recognise the concept of the occasional dwindling of 'therapeutic momentum', which presents as much a leadership as a clinical challenge. Clearly, this is not amenable to simulator training or, at the very least, it requires 'outside the box' thinking about how to create an appropriate simulation environment.

In an industrial context, the development of a detailed understanding of how resources and systems interact to produce an outcome is a prerequisite for quality control and improvement. Leaving aside equipment for a moment, the fundamental resources and systems needed for the care of the critically ill patient are (a) staff, (b) the ways that they interact with each other, and (c) the non-human elements of systems (such as hospital design, protocols, and working practices). Thus, the study of the function of people and teams at a detailed level is somewhat location-specific, and studies need to be scrutinised for transferable lessons. Many of the themes identified in the study of Fackler and colleagues [1], though undertaken in a single institution in North America, will resonate and should provoke reflection and research on local service delivery.

\section{Conclusions}

Effectiveness and efficiency of care of the critically ill patient are subject to a number of influences, including skills of individual physicians/nurses (technical and non-technical), teamworking in the ICU, and the ICU environment. Behavioural research has significant potential to elucidate these individual influences and their interactions. Better understanding of these human and non-human elements of the system of care of the critically ill patient is a prerequisite for design and successful implementation of interventions that can improve staff interactions and care delivery.

\section{Competing interests}

The authors declare that they have no competing interests.

\section{References}

1. Fackler J, Watts C, McHugh A, Miller T, Crandall B, Pronovost P: Critical care physician cognitive task analysis: an exploratory study. Crit Care 2009, 13:R33.

2. Vincent C, Moorthy K, Sarker SK, Chang A, Darzi AW: Systems approaches to surgical quality and safety: from concept to measurement. Ann Surg 2004, 239:475-482.

3. Undre S, Arora S, Sevdalis N: Surgical performance, human error and patient safety in urological surgery. $\mathrm{Br} J$ Med Surg Urol 2009, 2:2-10.

4. Yule S, Flin R, Paterson-Brown S, Maran N: Non-technical skills for surgeons. A review of the literature. Surgery 2006, 139: 140-149.

5. Undre S, Sevdalis N, Healey AN, Darzi A, Vincent CA: Teamwork in the operating theatre: cohesion or confusion? J Eval Clin Pract 2006, 12:182-189.

6. Healey AN, Undre S, Sevdalis N, Koutantji M, Vincent CA: The complexity of measuring interprofessional teamwork in the operating theatre. J Interprof Care 2006, 20:485-495.

7. Sevdalis N, Forrest D, Undre S, Darzi A, Vincent CA: Annoyances, disruptions and interruptions in surgery. The Disruptions in Surgery Index (DiSI). World J Surg 2008, 32: 1643-1650.

8. Sevdalis N, Healey AN, Vincent CA: Distracting communications in the operating theatre. J Eval Clin Pract 2007, 13:390394.

9. Reader T, Flin R, Lauche K, Cuthbertson BH: Non-technical skills in the intensive care unit. $\mathrm{Br} J$ Anaesth 2006, 96:551559.

10. Jeffcott SA, Mackenzie CF: Measuring team performance in healthcare: review of research and implications for patient safety. J Crit Care 2008, 23:188-196.

11. Lingard L, Espin S, Evans C, Hawryluck L: The rules of the game: interprofessional collaboration on the intensive care unit team. Crit Care 2004, 8:R403-408.

12. Reader T, Flin R, Mearns K, Cuthbertson BH: Interdisciplinary communication in the intensive care unit. $\mathrm{Br} J$ Anaesth 2007, 98:347-352.

13. Reader $\mathrm{T}$, Flin $\mathrm{R}$, Cuthbertson $\mathrm{BH}$. Communication skills and error in the intensive care unit. Curr Opin Crit Care 2007, 13: 732-736.

14. Thomas EJ, Sexton JB, Helmreich RL: Discrepant attitudes about teamwork among critical care nurses and physicians. Crit Care Med 2003, 31:956-959.

15. Alvarez G, Coiera E: Interdisciplinary communication: an uncharted source of medical error? J Crit Care 2006, 21:236242.

16. Alameddine M, Dainty KN, Deber R, Sibbald WJ: The intensive care unit work environment: current challenges and recommendations for the future. J Crit Care, 2008 Jul 18. [Epub ahead of print].

17. Alvarez G, Coiera $E$ : Interruptive communication patterns in the intensive care unit ward round. Int J Med Inform 2005, 74: 791-796.

18. Pronovost PJ, Berenholtz SM, Dorman T, Lipsett PA, Simmonds $\mathrm{T}$, Haraden $\mathrm{C}$ : Improving communication in the ICU using daily goals. J Crit Care 2003, 18:71-75.

19. Sundar E, Sundar S, Pawlowski J, Blum R, Feinstein D, Pratt S: Crew resource management and team training. Anesthesiol Clin 2007, 25:283-300. 